\title{
Triangulation: the holy grail of endoscopic surgery?
}

\author{
Daniel von Renteln • Melina C. Vassiliou • \\ Thomas Rösch $\cdot$ Richard I. Rothstein
}

Published online: 18 March 2011

(C) Springer Science+Business Media, LLC 2011

Interventional endoscopy has recently breached the boundaries of the gastrointestinal lumen, entering into the peritoneal cavity to perform natural orifice translumenal endoscopic surgery (NOTES) [1-3]. NOTES is defined as a surgical procedure in which visualization, dissection, and organ retraction is performed with flexible endoscopic instruments through the natural orifices of the body. NOTES is theoretically scarless, and therefore, incisional hernias and associated wound infections are avoided. Other potential benefits include reduced surgical trauma resulting in less postoperative pain and adhesion formation compared with laparoscopic surgery [3]. Currently, no randomized, controlled trial has demonstrated a true advantage of NOTES compared with laparoscopic surgery and the proposed benefits remain speculative. Thus far, and largely in animal laboratories, gastroenterologist and surgeon have opened and closed the gastrointestinal wall, peered into the peritoneal cavity, and demonstrated feasibility of organ resection $[4,5]$. Why is it that despite being eager to perform endoscopic intraperitoneal surgery, gastroenterologists and surgeons have only scratched the surface of this

D. von Renteln $(\varangle) \cdot$ T. Rösch

Department of Interdisciplinary Endoscopy, University Hospital

Hamburg-Eppendorf, Martinistraße. 52, 20246 Hamburg,

Germany

e-mail: renteln@gmx.net

M. C. Vassiliou

Department of Surgery, Montreal General Hospital,

McGill University, Montreal, Quebec, Canada

\section{R. I. Rothstein}

Section of Gastroenterology and Hepatology,

Department of Medicine, Dartmouth-Hitchcock Medical Center, Lebanon, NH, USA

e-mail: Richard.I.Rothstein@Hitchcock.ORG novel surgical approach, which is still nowhere near primetime?

When experts try to predict how NOTES could function, they normally look at the principles of laparoscopic surgery. Laparoscopic surgery is performed with careful placement of trocars to optimize exposure and to permit triangulation. It is assumed that triangulation is necessary to create traction and countertraction and that this physical principle is what permits appropriate retraction, dissection, or suturing. Accordingly, many experts have suggested that flexible endoscopic surgery will need to emulate the same principles of triangulation to be an effective surgical approach [6,7]. Several articles have proposed a triangulating endoscope as a key element for the success of NOTES [3, 8-11]. Consequently, NOTES research in recent years has been dominated by major efforts to develop devices and platforms that simulate triangulation and surgical tasks based on how they are performed in the laparoscopic environment. The first patent describing the concept of an endoscope with angulating end-effectors was filed by Mitsui for Olympus as early as 1974 (United States patent number $3,915,157)$. This patent was subsequently further refined and advanced to a prototype triangulating endoscopic platform filed for patent in 1999 (Matsui et al., United States Patent number 6,352,503). Despite these enduring efforts to build a triangulating endoscopic platform, no such device has become available for clinical use, and those among us who had the opportunity to work with triangulating prototypes have realized that triangulating end-effectors at the tip of a flexible endoscope may have inherited more problems than solutions.

Using the flexible translumenal instead of a laparoscopic approach for intraperitoneal surgery does not nullify surgical principles and certain tasks, such as robust organ retraction and classic suturing, will likely require triangulation. There 
also are some basic endoscopic principles that cannot be neglected by the endoscopic surgeon. One has to consider how endolumenal interventional endoscopy works. Interventional endoscopy depends on the flexible nature of the instrument to navigate the gastrointestinal tract to reach a target. Once a target is reached, the endoscopist uses dynamic scope stabilization and manipulation to accomplish an interventional procedure. The endoscope is rarely stable for very long, and controlling the flexible movement of the instrument is what makes interventional endoscopy possible. Consequently, two separately moving end-effectors permitting triangulation at the end of the endoscope might actually increase procedural instability instead of achieving effective countertraction, enhanced dissection, or the ability to suture.

Working with numerous prototype NOTES devices and platforms that allowed for angulation or triangulation, we have encountered several important limitations. First, and most importantly, additional angulation at the tip of a flexible instrument often decreases stability. Safe and controlled dissection using a flexible endoscope relies much more on stability than on triangulation once the target lesion is reached. Second, angulation at the tip of a flexible endoscope decreases and makes the tactile feedback less reliable. Third, once instruments become too complicated, they hinder more than help. A single operator with two hands is only able to control a limited number of buttons and wheels. Any functions added to the flexible endoscope that allow for more angles of movement freedom, more capabilities, more control wheels, buttons, and levers will lead to practical limitations due to increased complexity. Consequently, every additional function achieving enhanced triangulation has to be reviewed for its trade-offs in robustness, stability, and practicality. For example, it might be better to adapt the concept of suturing to the endoscopic environment instead of trying to build an endoscope or platform that can imitate laparoscopic suturing [4, 9, 12-18].

We might not succeed by trying to mimic with our endoscopes the traditional activities of the surgeon performing open or laparoscopic procedures. Consequently, we will need to define key needs and requirements for each surgical task based on concepts that can effectively work in a flexible endoscopic environment. A multipurpose triangulating endo-surgical platform might allow us to simulate all laparoscopic tasks with a single device, but depending on the task the new platform might appear deficient in comparison to its laparoscopic counterpart. Mimicking the surgeon with triangulating end-effectors at the tip of a flexible endoscope may provide some entertaining videos demonstrating that a needle can be passed through tissue and a knot can be tied.

Rarely is it disclosed that such platforms take an inordinately long time to complete such tasks and are, at present, no competition to laparoscopic surgery. Chasing the best triangulating platform might end up being chasing some Holy Grail, believing in its miraculous powers. In the tale of the Holy Grail, Percival's immaturity prevents the hero from fulfilling his destiny, and he must grow spiritually and mentally before he can locate the grail again. We believe that it will take more than the quest to mimic surgical tasks for flexible endoscopic surgery to succeed. It will take imagination, ingenuity, and the willingness to (again) break the boundaries of new dogmas and old concepts.

Flexible endoscopic surgery is something new and an open iterative process. It is more than laparoscopic surgery performed with an endoscope traversing a viscus. If we open our minds to create a vision of endoscopic ingenuity grounded in surgical principles, we might finally encounter surgery without scalpels or visible scars. Or, as Bernard Lown put it: "Only those who can see the invisible can do the impossible."

Disclosures Daniel von Renteln, Melina C. Vassiliou, Thomas Rösch, and Richard I. Rothstein declare that they have no conflicts of interest or financial ties to disclose.

\section{References}

1. Horgan S, Cullen JP, Talamini MA, Mintz Y, Ferreres A, Jacobsen GR, Sandler B, Bosia J, Savides T, Easter DW, Savu MK, Ramamoorthy SL, Whitcomb E, Agarwal S, Lukacz E, Dominguez G, Ferraina P (2009) Natural orifice surgery: initial clinical experience. Surg Endosc 23:1512-1518

2. Marks JM, Ponsky JL, Pearl JP, McGee MF (2007) PEG "Rescue": a practical NOTES technique. Surg Endosc 21:816-819

3. Rattner D, Kalloo A (2006) ASGE/SAGES Working Group on Natural Orifice Translumenal Endoscopic Surgery. October 2005. Surg Endosc 20:329-333

4. von Renteln D, Eickhoff A, Kaehler G, Riecken B, Caca K (2009) Endoscopic closure of the natural orifice transluminal endoscopic surgery (NOTES) access site to the peritoneal cavity by means of transmural resorbable sutures: an animal survival study. Endoscopy 41:154-159

5. von Renteln D, Schmidt A, Vassiliou MC, Gieselmann M, Caca K (2009) Natural orifice transluminal endoscopic surgery gastrotomy closure with an over-the-endoscope clip: a randomized, controlled porcine study (with videos). Gastrointest Endosc 70:732-739

6. Spaun GO, Zheng B, Swanstrom LL (2009) A multitasking platform for natural orifice translumenal endoscopic surgery (NOTES): a benchtop comparison of a new device for flexible endoscopic surgery and a standard dual-channel endoscope. Surg Endosc 23:2720-2727

7. Thompson CC, Ryou M, Soper NJ, Hungess ES, Rothstein RI, Swanstrom LL (2009) Evaluation of a manually driven, multitasking platform for complex endoluminal and natural orifice transluminal endoscopic surgery applications (with video). Gastrointest Endosc 70:121-125

8. Nakao NL (2007) Deconstruction of the endoscope: completing my wish list. Gastrointest Endosc 66:997-1000

9. Eisenberg D, Storne E, Belson A (2010) Use of a flexible robotic transgastric natural orifice translumenal endoscopic surgery 
(NOTES) platform in a cadaver to test access, navigation, maneuverability, and stability. Surg Endosc 24:2323

10. Lehman AC, Dumpert J, Wood NA, Redden L, Visty AQ, Farritor S, Varnell B, Oleynikov D (2009) Natural orifice cholecystectomy using a miniature robot. Surg Endosc 23:260-266

11. Scott DJ, Tang SJ, Fernandez R, Bergs R, Goova MT, Zeltser I, Kehdy FJ, Cadeddu JA (2007) Completely transvaginal NOTES cholecystectomy using magnetically anchored instruments. Surg Endosc 21:2308-2316

12. von Renteln D, Schmidt A, Riecken B, Caca K (2008) Gastric full-thickness suturing during EMR and for treatment of gastricwall defects (with video). Gastrointest Endosc 67:738-744

13. Austin RC, Mosse CA, Swain P (2009) A novel use of T-tag sutures for the safe creation and closure of the NOTES gastrotomy using a hybrid technique. Surg Endosc 23:2827-2830

14. Gee DW, Willingham FF, Lauwers GY, Brugge WR, Rattner DW (2008) Natural orifice transesophageal mediastinoscopy and thoracoscopy: a survival series in swine. Surg Endosc 22:2117-2122
15. Meireles OR, Kantsevoy SV, Assumpcao LR, Magno P, Dray X, Giday SA, Kalloo AN, Hanly EJ, Marohn MR (2008) Reliable gastric closure after natural orifice translumenal endoscopic surgery (NOTES) using a novel automated flexible stapling device. Surg Endosc 22:1609-1613

16. Mintz Y, Horgan S, Cullen J, Falor E, Talamini MA (2008) Duallumen natural orifice translumenal endoscopic surgery (NOTES): a new method for performing a safe anastomosis. Surg Endosc 22:348-351

17. Moyer MT, Pauli EM, Gopal J, Mathew A, Haluck RS (2011) Durability of the self-approximating translumenal access technique (STAT) for potential use in natural orifice translumenal surgery (NOTES). Surg Endosc 25:315-321 discussion 321-312

18. Sherwinter DA, Gupta A, Cummings L, Eckstein JG (2010) Evaluation of a modified circular stapler for use as a viscerotomy formation and closure device in natural orifice surgery. Surg Endosc 24:1456-1461 